\title{
Characterization of Skeletal Muscle Endocrine Control in an In Vitro Model of Myogenesis
}

\author{
Cecilia Romagnoli ${ }^{1}$ (C) $\cdot$ Roberto Zonefrati $^{1} \cdot$ Preeti Sharma $^{1} \cdot$ Marco Innocenti $^{2} \cdot$ Luisella Cianferotti $^{1}$. \\ Maria Luisa Brandi ${ }^{1}$ (D)
}

Received: 7 November 2019 / Accepted: 14 February 2020 / Published online: 27 February 2020

(c) The Author(s) 2020

\begin{abstract}
Skeletal muscle has remarkable regenerative abilities regulated by a highly orchestrated process involving the activation of cellular and molecular responses, which are dependent on satellite cells. These cells maintain the stem cell population and provide numerous myogenic cells that proliferate, differentiate, fuse and lead to new myofiber formation for a functional contractile tissue. We have isolated and characterized satellite cells obtained from human biopsies and established an in vitro model of myogenesis, evaluating muscle regeneration, monitoring the dynamic increases of the specific myogenic regulatory factors and the final formation of multinucleated myofibers. As the skeletal muscle is an endocrine tissue able of producing many substances that can act on distant organs, and it can be physiologically modulated by a variety of hormones, we embarked in a project of characterization of muscle cell endocrinology machinery. The expression of a large array of hormone receptors was quantified during the process of myogenesis. The results obtained showed a significant and generalized increase of all the tested hormone receptors along the process of differentiation of human cultured cells from myoblasts to myocytes. Interestingly, also the production of the myokine irisin increased in a parallel manner. These findings point to the human cultured myoblasts as an ideal model to characterize the skeletal muscle endocrine machinery and its hormonal regulation.
\end{abstract}

Keywords Skeletal muscle $\cdot$ Satellite cells $\cdot$ Myogenesis $\cdot$ Skeletal muscle endocrinology $\cdot$ Hormone receptors

$\begin{array}{ll}\text { Abbreviations } \\ \text { VDR } & \text { Vitamin D receptor } \\ \text { TR } \alpha & \text { Thyroid receptor } \alpha \\ \text { TR } \beta & \text { Thyroid receptor } \beta\end{array}$

Maria Luisa Brandi

marialuisa.brandi@unifi.it

Cecilia Romagnoli

cecilia.romagnoli@unifi.it

Roberto Zonefrati

roberto.zonefrati@unifi.it

Preeti Sharma

preeti.sharma@unifi.it

Marco Innocenti

marco.innocenti@unifi.it

Luisella Cianferotti

luisella.cianferotti@unifi.it

1 Department of Experimental and Clinical Biomedical Sciences, University of Florence, Largo Palagi 1, 50139 Florence, Italy

2 Department of Health Sciences, University of Florence, Viale Pieraccini 6, 50139 Florence, Italy
GCR Glucocorticoid receptor

PTH-1R Parathyroid hormone receptor-1

IFG-1R Insulin-like growth factor 1 receptor

LRP-5 Low-density lipoprotein receptor-related protein 5

LRP-6 Low-density lipoprotein receptor-related protein 6

PAX-7 Paired box protein 7

MRFs Myogenic regulatory factors

MHC Myosin heavy chain

hSkMC Human skeletal muscle-derived cells

SCs Satellite cells

\section{Introduction}

Skeletal muscle is the most abundant tissue in the human body, accounting for about $40-45 \%$ of total body weight. It plays an important role in controlling physical activity, including voluntary locomotion, postural behavior, and breathing. Moreover, it has an extraordinary ability to adapt to physiological demands, such as growth, and 
to regenerate new muscle fibers after damage by injury or intense physical activity [1].

The regeneration and remodeling of skeletal muscles are extremely complex biological processes, in which skeletal muscle stem cells (also known as satellite cells, SCs) are involved. The SCs are located under the basal lamina of the myofiber; this position, between the myofiber and the surrounding extracellular matrix (ECM), is the reason Alexander Mauro gave them this name in 1961 [2]. In healthy adult mammalian muscle, SCs are predominantly quiescent (phase $\mathrm{G}_{0}$ ) and represent $2.5-6 \%$ of all nuclei of a given fiber; however, after injury or degeneration, SCs become activated and can generate large numbers of new myofibers within just few days [3]. Like stem cells, satellite cells also self-renew to maintain their own population, re-establishing their numbers and quiescent state by homing back to highly specialized niches, thus allowing future rounds of regeneration [4]. Specific temporal factors, called Myogenic Regulatory Factors (MRFs), members of the basic helix-loop-helix (bHLH) family of transcription factors including Myf-5, MyoD1, Myogenin and MRF4, are an essential group of four muscle-specific proteins responsible for acting at multiple points in the muscle lineage to cooperatively establish the skeletal muscle phenotype $[4,5]$.

Besides its well-known structural and biomechanical functions for the purpose of movement, the skeletal muscle is considered a secretory organ, capable of producing several substances called myokines, which can act on the muscle itself, on nearby tissues, and on distant organs, in an autocrine, paracrine and endocrine fashion, respectively [6-8]. These functions can be physiologically modulated by physical stimuli and by cytokines, mineral ions and hormones, or can be modified by sarcopenia, morphological modification of muscle fibers and/or endocrinopathies.

The evaluation of the skeletal muscle as a secretory organ is not fully understood, neither it is the endocrine control of muscle function and differentiation [9]. A future chapter in the endocrine discipline will certainly be musclecrinology. The aim of our study was to evaluate the endocrine machinery in an in vitro cellular model of myogenesis obtained from human skeletal muscle biopsies. The understanding of hormonal production and regulation in the skeletal muscle remodeling may contribute to the identification of new possible therapeutic targets in pathologies in which the myogenesis and/or the function of mature myocytes is affected.

\section{Materials and Methods}

\section{Isolation of Human Skeletal Muscle-Derived Cells (hSkMCs)}

Primary cultures were isolated from human skeletal muscle biopsies of 3 healthy adult volunteers undergoing plastic surgery, after signing an informed consent in accordance with a protocol approved by the Local Ethics Committee of AOU Careggi, Firenze (Italy), for human studies (Rif. N. 14.017), as well as the ethical standards stated in the Declaration of Helsinki (1964) and its later amendments or comparable ethical standards. The minced specimens were processed within $3 \mathrm{~h}$ from the operation and enzymatically digested for $3 \mathrm{~h}$ at $37^{\circ} \mathrm{C}$ in Ham's F12 Coon's modification medium (Sigma-Aldrich) supplemented with $20 \%$ fetal bovine serum (FBS) and $3 \mathrm{mg} / \mathrm{ml}$ collagenase type I (C-0130, SigmaAldrich). The tissues were then mechanically dispersed by pipetting and passed through a sterile $100 \mu \mathrm{m}$ stainless steel tissue sieve to remove any large debris. The undigested tissue trapped in the sieve was discarded, while the infranatant containing the hSkMC fraction was collected and the cells sedimented by centrifugation at $300 \times g$ for $5 \mathrm{~min}$. The cells were then pre-plated into $100 \mathrm{~mm}$ Petri dishes for $1 \mathrm{~h}$ at $37{ }^{\circ} \mathrm{C}$ to remove fibroblasts which adhere to plastic more avidly than satellite cells. Afterwards, the resulting suspension was seeded in $100 \mathrm{~mm}$ tissue culture plates at $37^{\circ} \mathrm{C}$ in humidified atmosphere with $5 \% \mathrm{CO}_{2}$ using a skeletal muscle cell growth medium (GM) composed of Skeletal Muscle Cell Basal Medium (PromoCell GmbH, cod. C-23260) supplemented with 5\% Fetal Calf Serum (FCS), $50 \mu \mathrm{g} / \mathrm{ml}$ fetuin, $10 \mathrm{ng} / \mathrm{ml}$ Epidermal Growth Factor (EGF), $1 \mathrm{ng} / \mathrm{ml}$ basic Fibroblast Growth Factor (bFGF), $10 \mu \mathrm{g} / \mathrm{ml}$ insulin, $0.4 \mu \mathrm{g} / \mathrm{ml}$ dexamethasone and $100 \mathrm{IU} / \mathrm{ml}$ penicillin, $100 \mu \mathrm{g} /$ $\mathrm{ml}$ streptomycin (Table 1). The medium was refreshed twice a week and the cells were used for further subculturing or cryopreservation upon reaching $5 \times 10^{3}$ cells $/ \mathrm{cm}^{2}$. Cells at the early passages (from 1 to 4 ) were used for all

Table 1 Supplements and concentrations after their addition to the basal medium for growth medium and myogenic differentiation medium used in the experiments, respectively

\begin{tabular}{lll}
\hline & Growth medium & $\begin{array}{l}\text { Myogenic } \\
\text { differentiation } \\
\text { medium }\end{array}$ \\
\hline Fetal calf serum & $0.05 \mathrm{ml} / \mathrm{ml}$ & - \\
Fetuin & $50 \mu \mathrm{g} / \mathrm{ml}$ & - \\
Epidermal growth factor & $10 \mathrm{ng} / \mathrm{ml}$ & - \\
Basic fibroblast growth factor & $1 \mathrm{ng} / \mathrm{ml}$ & - \\
Insulin & $10 \mu \mathrm{g} / \mathrm{ml}$ & $10 \mu \mathrm{g} / \mathrm{ml}$ \\
Dexamethasone & $0.4 \mu \mathrm{g} / \mathrm{ml}$ & -
\end{tabular}


the experiments. All tissue culture plates utilized for cell amplification and experiments were previously coated with Matrigel ${ }^{\circledR}$ (BD Biosciences) in order to increase cell attachment, proliferation and to maintain cell phenotype [10].

\section{hSkMC Characterization and Multipotency Evaluation}

The characterization of the hSkMC cell lines was performed analyzing the presence of the surface markers of mesenchymal stem cells and specific markers of the isolated satellite cells by flow cytometry analysis and by studying their multipotency toward the myogenic, the adipogenic and the osteogenic phenotypes, as previously described [11].

\section{Flow Cytometry}

hSkMC lines were evaluated by flow cytometry with a CyFlowßSpace cytometer (Sysmex Partec), equipped with FlowMax ${ }^{\circledR}$ software. The antibodies used (Abcam) were directed against the following antigens (the tags are given in parentheses): CD44 (PE/Cy7), CD90 (APC), CD105 (FITC), CD45 (PerPC), CD34 (PE) and CD56 (PerCP Cy5.5) and PAX-7 (FITC). Each antibody was diluted according to manufacturer's instruction. Briefly, $1 \times 10^{5}$ cells were labeled with antibodies in PBS with $1 \%$ bovine serum albumin (BSA) for 20 min RT in the dark, then washed once and promptly analyzed.

\section{Myogenic Differentiation}

hSkMC lines at $70 \%$ of confluence were cultured with a specific myogenic medium (MM): Skeletal Muscle Cell Basal Medium (PromoCell GmbH, cod. C 23260) supplemented with $10 \mu \mathrm{g} / \mathrm{ml}$ insulin, $100 \mathrm{IU} / \mathrm{ml}$ penicillin and $100 \mu \mathrm{g} / \mathrm{ml}$ streptomycin. The medium was refreshed twice a week. The expression of the myogenic phenotype was evaluated by microscopic observations of the multinucleated cells formation, by immunofluorescence of the myosin heavy chain (MHC) and by gene expression analysis, after 10 days of induction (Table 1).

\section{Adipogenic Differentiation}

hSkMC lines were cultured with a specific adipogenic medium (AM): Ham's F12 Coon's modification medium supplemented with $10 \%$ (FBS), $100 \mathrm{IU} / \mathrm{ml}$ penicillin, $100 \mu \mathrm{g} / \mathrm{ml}$ streptomycin and $1 \mu \mathrm{M}$ dexamethasone, $1 \mu \mathrm{M}$ bovine insulin, $0.5 \mathrm{mM}$ isobutylmethylxanthine (IBMX). The medium was refreshed twice a week. The expression of the adipogenic phenotype was evaluated on cells cultured in AM for 10 days by cytochemical staining with Oil Red O and brightfield observations (Axiovert 200, Zeiss).

\section{Osteogenic Differentiation}

hSkMCs were plated on tissue culture dishes at a cell density of $1 \times 10^{4}$ cells $/ \mathrm{cm}^{2}$ and grown to $70-80 \%$ confluence. Afterwards, the medium was switched to osteogenic medium (OM): Ham's F12 Coon's modification medium supplemented with $10 \% \mathrm{FBS}, 100 \mathrm{IU} / \mathrm{ml}$ penicillin, $100 \mu \mathrm{g} / \mathrm{ml}$ streptomycin, $10 \mathrm{nM}$ dexamethasone, $0.2 \mathrm{mM}$ sodium L-ascorbyl-2-phosphate, and $10 \mathrm{mM} \beta$-glycerol phosphate. The medium was refreshed twice a week. The expression of the osteoblastic phenotype was evaluated at 20 days from induction by monitoring the production of mineralized nodules by cytochemical staining. The cells were washed with DPBS (two times), fixed in 4\% paraformaldehyde (PFA)/DPBS for $15 \mathrm{~min}$, and washed with ultrapure water (three times). Calcium mineral deposits were stained with $1 \mu \mathrm{g} / \mathrm{ml}$ calcein added to the OM and nuclei were counterstained with $1 \mu \mathrm{g} / \mathrm{ml}$ bisbenzimide for $5 \mathrm{~min}$; calcium mineralized deposits were stained in fluorescent green, nuclei in blue, and then visualized in epifluorescence microscopy (Axiovert 200, Zeiss).

\section{Immunofluorescence}

hSkMCs were seeded into 24 -well plates $\left(1 \times 10^{4}\right.$ cells/ well) and cultured for $24 \mathrm{~h}$ in GM. Afterwards, cells were fixed for 10 min with $4 \%$ paraformaldehyde and permeabilized for 10 min with $0.2 \%$ Triton X 100 at RT. Cells were treated for another $30 \mathrm{~min}$ at $37{ }^{\circ} \mathrm{C}$ with RNAse in $2 \%$ bovine serum albumin (BSA) in order to degrade RNA and block non-specific sites. Samples were then incubated overnight with primary antibody for PAX-7 and MHC (Abcam, Cambridge, UK) in PBS at $4{ }^{\circ} \mathrm{C}$. After extensive washes with PBS, goat anti-mouse $\operatorname{IgG}(\mathrm{H}+\mathrm{L})$ SuperClonal secondary antibody, Alexa Fluor 488 conjugate (Thermo Fischer Scientific, Waltham, MA, USA) was incubated for $1 \mathrm{~h}$ at room temperature in the dark. Subsequently, nuclei were counterstained with $10^{-5} \mathrm{M}$ propidium iodide. Samples were then washed with PBS for observation in laser scanning confocal microscopy (LSCM), using an LSM 510 Meta microscope (ZEISS, Oberkochen, Germany) [12].

\section{RNA Extraction and Real-Time qPCR Analysis}

Gene expression analysis in the hSkMCs was performed in GM and after 9 days of induction in MM. The genes included in the analysis were PAX-7, MyoD-1, Myf-5, MRF-4, Myogenin, Desmin, MHC, Irisin, and specific hormone receptor genes (VDR, TR $\alpha$, TR $\beta$, GCR, IGF-1, PTH1R, LRP-5, LRP6). Target gene expression was normalized to $40 \mathrm{~S}$ ribosomal 
Table 2 Primers and TaqMan probes used for the experiments

\begin{tabular}{|c|c|c|c|}
\hline Gene & Primer sequences $\left(5^{\prime}-3^{\prime}\right)$ and TaqMan probes & $\begin{array}{l}\text { Amplicon } \\
\text { size (bp) }\end{array}$ & $T_{\mathrm{m}}\left({ }^{\circ} \mathrm{C}\right)$ \\
\hline PAX-7 for & GGTACCGAGAATGATGCGG & 124 & 55 \\
\hline PAX-7 rev & CCCATTGATGAAGACCCCTC & & \\
\hline Pax-7 Probe & 6-FAM/AGCTGATTG/Zen/ACCCGGCCTTGG/3IABkFQ & & \\
\hline MyoD-1 for & GACGTGCCTTCTGAGTCG & 148 & 55 \\
\hline MyoD-1 rev & CTCAGAGCACCTGGTATATCG & & \\
\hline MyoD-1 Probe & 6-FAM/CGCTGCTCT/Zen/CTCCCTCGCTG/3IABkFQ & & \\
\hline Myf-5 for & ATGCCATCCGCTACATCG & 145 & 55 \\
\hline Myf-5 rev & ACAGGACTGTTACATTCGGC & & \\
\hline Myf-5 Probe & 6-FAM/CCCCACCTC/Zen/CAACTGCTCTGAT/3IABkFQ & & \\
\hline MRF-4 for & CCCTGGAATGATCGGAAACA & 95 & 55 \\
\hline MRF-4 rev & CTTCAGCTACAGACCCAAACA & & \\
\hline MRF-4 Probe & 6-FAM/ATCTTGAGG/ZEN/GTGCGGATTTCCTGC/3IABkFQ & & \\
\hline Myogenin for & AGCGAATGCAGCTCTCAC & 150 & 55 \\
\hline Myogenin rev & TGTGATGCTGTCCACGATG & & \\
\hline Myogenin Probe & 6-FAM/TGACCCTAC/Zen/AGATGCCCACAACC/3IABkFQ & & \\
\hline MHC for & GAGTCCTTTGTGAAAGCAACAG & 143 & 55 \\
\hline MHC rev & GCCATGTCCTCGATCTTGTC & & \\
\hline MHC Probe & 6-FAM/CAAGTCTTC/Zen/CCCATGAACCCTCCC/3IABkFQ & & \\
\hline Desmin for & AACGCGATCTCCTCGTTG & 101 & 55 \\
\hline Desmin rev & GAGAACAATTTGGCTGCCTTC & & \\
\hline Desmin Probe & 6-FAM/CAATTCTGC/ZEN/GCTCCAGGTCAATGC/3IABkFQ & & \\
\hline VDR for & CCGCATCACCAAGGACAA & 112 & 62 \\
\hline VDR rev & СТTCCTCTGCACTTCCTCATC & & \\
\hline VDR Probe & 6-FAM/TGTGGACAT/ZEN/CGGCATGATGAAGGA/3IABkFQ & & \\
\hline $\mathrm{TR} \alpha$ for & TCCCTAGTTACCTGGACAAAGA & 133 & 59 \\
\hline TR $\alpha$ rev & GGATGGAGGTTCTTCTGGATTG & & \\
\hline TR $\alpha$ Probe & 6-FAM/ACAGCGGTA/ZEN/GTGATAACCAGTTGCC/3IABkFQ & & \\
\hline $\operatorname{TR} \beta$ for & CTTCCAAACGGAGGAGAAGAA & 115 & 59 \\
\hline $\operatorname{TR} \beta$ rev & CGTGATACAGCGGTAGTGATAC & & \\
\hline TR $\beta$ Probe & 6-FAM/TGTGTAGTG/ZEN/TGTGGTGACAAAGCCA/3IABkFQ & & \\
\hline GCR for & TGGTCCTGTTGTTGCTGTT & 103 & 55 \\
\hline GCR rev & CTTCCCTGGTCGAACAGTTT & & \\
\hline GCR Probe & 6-FAM/TAAGCTCTC/ZEN/CTCCATCCAGCTCCT/3IABkFQ & & \\
\hline IGF-1 for & CAGCAAGTGAGGAGAGGAAC & 131 & 59 \\
\hline IGF-1 rev & GTGTGAGAAGACCACCATCAA & & \\
\hline IGF-1 Probe & 6-FAM/TCGAAGAGA/ZEN/GCAAATGCACATCCCT/3IABkFQ & & \\
\hline LRP-5 for & CCCAGTCTGTCCAGTACATG & 134 & 59 \\
\hline LRP-5 rev & CTCAGAGACCAACCGCATC & & \\
\hline LRP-5 Probe & 6-FAM/CCAACCTCA/ZEN/ATG/3IABkFQ & & \\
\hline LRP-6 for & CCCATTTGTGTTTGATGTCTCC & 137 & 60 \\
\hline LRP-6 rev & CAAGTCTGTCCTTCGAGCTAAA & & \\
\hline LRP-6 Probe & 6-FAM/AAACCTGCA/ZEN/AAGATGGTGCCACAG/3IABkFQ & & \\
\hline PTH-1R for & GGGAAGCCCAGGAAAGATAAG & 125 & 58 \\
\hline PTH-1R rev & CACAGGATGTGGTCCCATT & & \\
\hline PTH-1R Probe & 6-FAM/TGCCTCCTT/ZEN/GTCCTCCTCAGACTC/3IABkFQ & & \\
\hline Irisin for & ACTATGTACTCCGTATCCTCCTC & 126 & 55 \\
\hline Irisin Rev & TGTCATCGGATTTGCCATCT & & \\
\hline Irisin Probe & 6-FAM/CCAGCAGAA/ZEN/GAAGGATGTGTCGGAT/3IABkFQ & & \\
\hline RPS18 for & GATGGCAAAGGCTATTTTCCG & 132 & 60 \\
\hline RPS18 rev & TCTTCCACAGGAGGCCTAC & & \\
\hline RPS18 Probe & 6-FAM/TTCAGGGAT(ZEN/CACTAGAGACATGGCTGC/3IABkFQ & & \\
\hline
\end{tabular}

TaqMan probes with $\mathrm{F}$ as reporter fluorochrome (6-carboxyfluorescein [6-FAM]) and ZEN as quencher. Fluorochrome (Iowa Black FQ); $b p$ base pairs of amplicon size; $T_{\mathrm{m}}$ melting temperature $\left({ }^{\circ} \mathrm{C}\right.$ ) 
protein S18 (RPS18). All procedures for amplification were previously described [13] (Table 2).

\section{Statistical Analysis}

All gene expression analyses were performed in tetraplicate and each experiment was repeated three times. All data were expressed as means \pm SD and are the number of mRNA molecules of the specific genes normalized to the housekeeping RPS 18 mRNA. Statistical differences among mean values were analyzed using ANOVA and a post hoc sequentially rejective multiple Bonferroni test, with predetermined (default) experimentwise probability $\alpha_{\mathrm{T}}=0.05$, comparing two groups: the value of the specific gene after 9 days of myogenic induction with respect to the control in proliferating medium.

\section{Results}

\section{Isolation and Characterization of hSkMCs}

The cell populations derived from human skeletal muscle biopsies (Fig. 1a), obtained by surgical resection, were amplified in Matrigel ${ }^{\circledR}$ coated plates in order to increase cell adherence and maintain cell phenotype. In fact, the isolated cells, when plated for the first time in a dish (passage 0), attach showing a rounded shape that persists for 2-3 days, with a slow proliferation rate (Fig. 1b). After that period, cells become flatter and show an elongated morphology with 2-4 cytoplasmic extensions (Fig. 1c).

Expanded cells were subsequently characterized by flow cytometry in order to verify their phenotype, analyzing the cluster of differentiation (CD) marker surface proteins (CD44, CD90, CD105, CD56, CD34, CD45) and one of the most reliable markers of the satellite cells (PAX-7).
The phenotype analysis revealed that isolated hSkMCs expressed the surface markers CD44, CD90, CD105, commonly used to identify mesenchymal stem cells, with a very high percentage of positiveness. In contrast, the hematopoietic lineage marker CD45 was negative. Regarding PAX-7, analysis showed the presence of the nuclear transcription factor in $99.12 \%$ of total cells (Fig. 2a). On the contrary, CD34 and CD56, commonly used to identify satellite cells derived from mouse skeletal muscle, turned out to be nonspecific for satellite cells derived from human skeletal muscle tissues; in fact, their presence on the cell surface is close to $0 \%$ and $9 \%$, respectively (Fig. 2).

Immunofluorescent staining of PAX-7, observed in LSCM, allowed the expression of the nuclear marker to be assessed. As expected from cytometry, it is clearly shown that the PAX-7 protein is present in the nuclei in all the expanded hSkMCs, confirming the isolation of human satellite cells (Fig. 2b).

Moreover, the gene expression of PAX-7 was analyzed over time, to verify its presence at cellular passages used for the experiments. As shown by Real-Time qPCR, we confirmed PAX-7 presence, but, as the passages increase, the gene expression of PAX-7 decreases, reducing the differentiating potential of cells (Fig. 2c). For that reason, we have limited the use of hSkMCs to passage 4 .

\section{Multipotentiality of hSkMCs}

The multipotent evaluation of hSkMCs was assessed by the induction toward the adipogenic, osteogenic and myogenic phenotypes, using appropriate media described in "Materials and Methods" section.

Adipogenic differentiation was performed culturing the hSkMCs in AM for 7 days, and confirmed, using Oil Red O staining, by the multiple intracellular lipid-filled droplets accumulation and microscopic observations in brightfield.
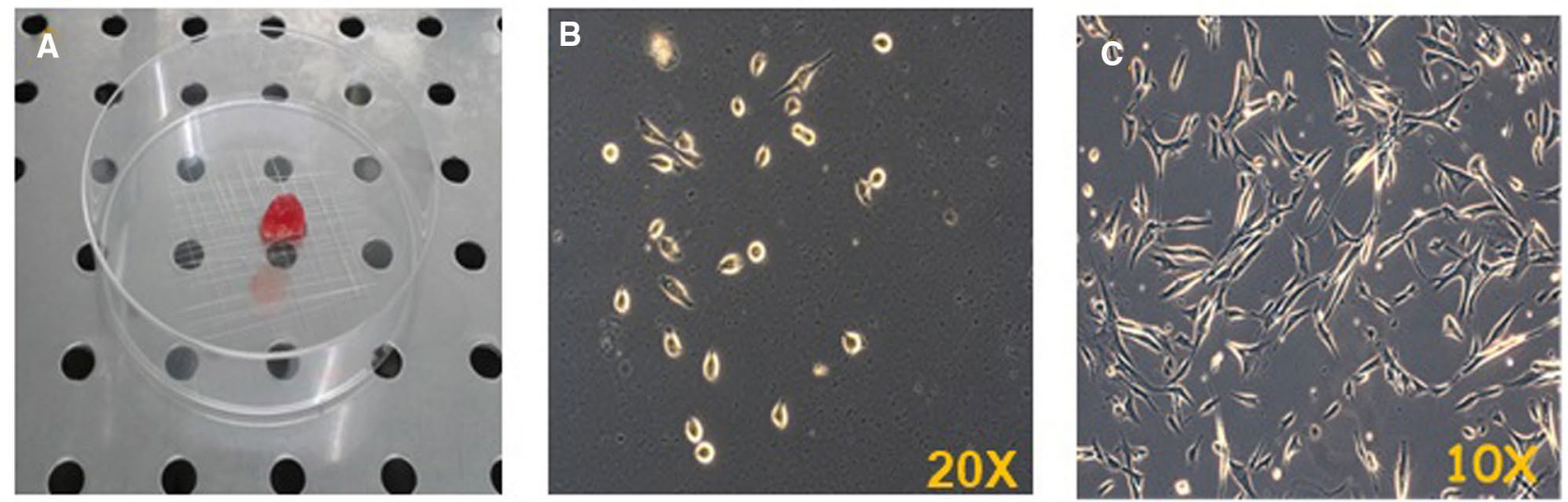

Fig. 1 Photo of human skeletal muscle biopsy (a); representative observations of primary culture of hSkMCs in phase contrast microscopy at passage 0 after 1 day in the dish; objective $\times 20$ (b) and after 3 days in the dish; objective $\times 10$ s $(\mathbf{c})$ 

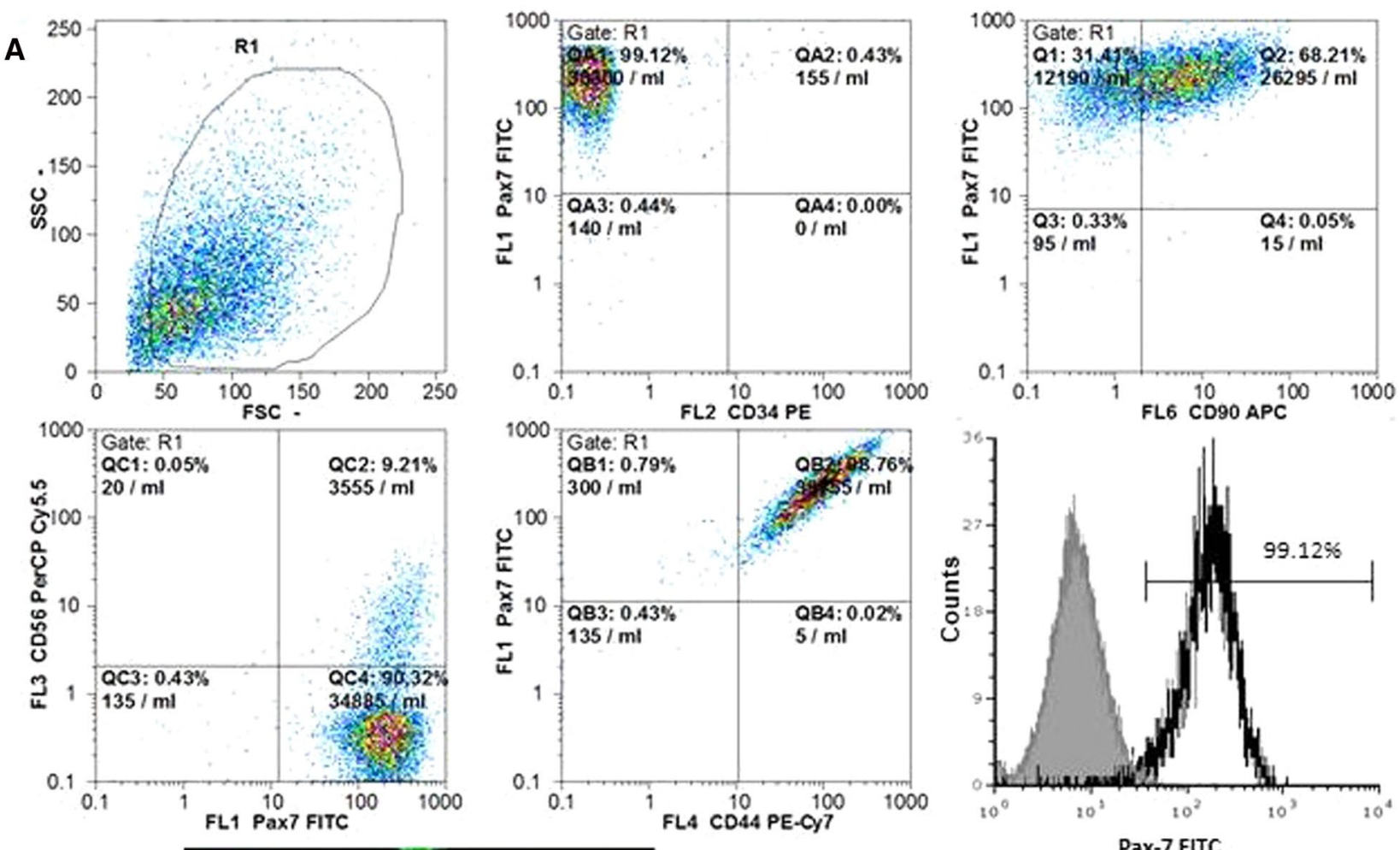

B

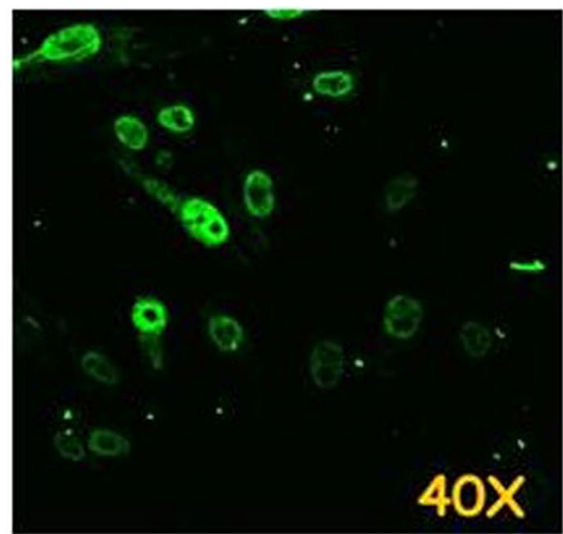

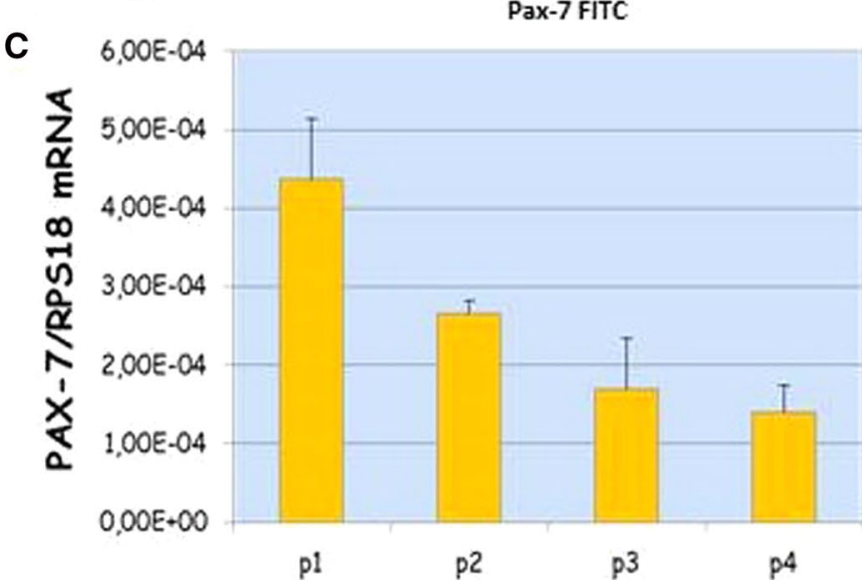

Fig. 2 Scattergrams of phenotype characterization of hSkMCs by flow cytometry analysis. The overlay plot shows the percentage of hSkMCs expressing the nuclear marker PAX-7 (open histogram); grey histogram: autofluorescence of unstained cells (a); Observation

in LSCM of the nuclear transcription factor of satellite cells PAX-7, objective $\times 40$ (b); Real-Time qPCR of the PAX-7 gene during passages (from 1 to 4 ) of hSkMCs. Data are normalized for the housekeeping gene RPS18 (c)

Afterwards, the hSkMCs were differentiated toward In contrast, control cells grown in GM for the same time did not show any formation of lipid droplets (Fig. 3a, b).

Osteogenic induction of hSkMCs was assessed with OM up to 15 days and observed monitoring the production of the mineralized calcium deposits, thanks to the fluorophore calcein added to the medium. Epifluorescence microscopic observations have shown calcein uptake in the calcium nodules after 15 days of osteogenic induction; in contrast, the control cells grown in GM for the same time did not show any deposition of calcium deposits (Fig. 3c, d). the myogenic phenotype using DM for 9 days. During this period, cells started to approach one another, fusing with one another. Observations in phase contrast microscopy have revealed the presence of multinucleated elongated cells (containing from 3 to more than 8 nuclei) referable to myotubes (Fig. 3e, f).

In order to confirm the myogenic induction of hSkMCs, we have performed, using Real-Time qPCR, the analysis of the MRFs (MyoD-1, Myf-5, MRF-4, Myogenin), the 
Fig. 3 Adipogenic phenotype evaluation of the hSkMCs.

Representative images of the adipogenic phenotype evaluation of skeletal muscle-derived cells at time 0 (a) and after 7 days of induction (b). The intracellular lipid droplets are stained in red by Oil Red O, and nuclei counterstained with Mayer's acid hemalum in blue. Images acquired in brightfield microscopy. Objective $\times 20$. Osteogenic phenotype evaluation of the hSkMCs. Representative images of calcium staining at time 0 (c) and after 15 days of osteogenic induction (d). The mineralized calcium deposits are in fluorescent green and nuclei counterstained with propidium iodide in conventional blue color. Images acquired in epifluorescence microscopy. Objective $\times 10$. Representative images in phase contrast microscopy of the multinucleated cells after 9 days of myogenic induction $(\mathbf{e}, \mathbf{f})$. The arrows show the formed myotubes. Objectives $\times 20$
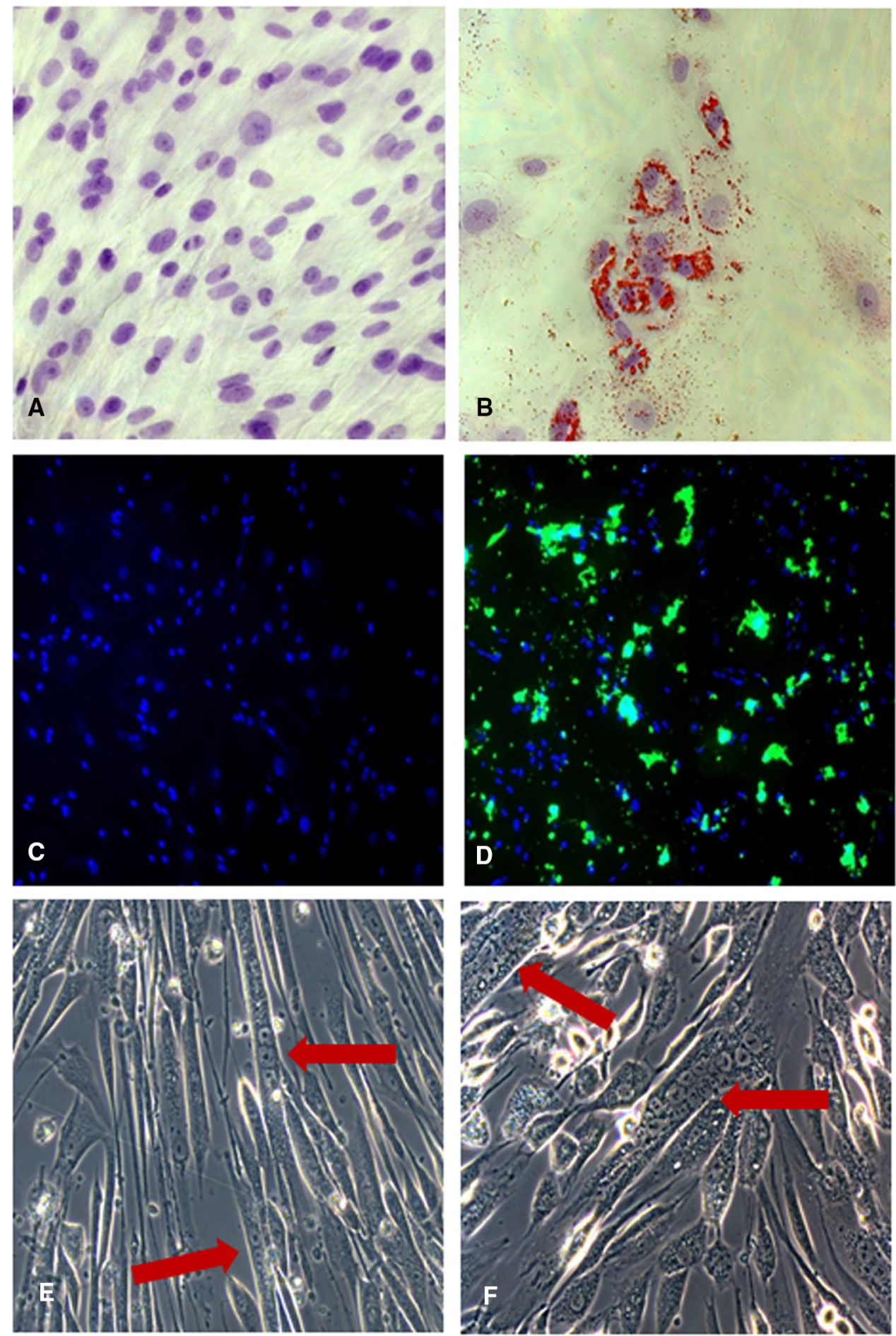

main myogenic differentiation genes, Desmin and MHC, after cultivating cells in MM up to 9 days. The results have shown a significant increase in the expressions of these genes during myogenesis, except for Myf-5, with respect to the control in GM (Time 0), indicating that differentiation occurred (Fig. 6). Moreover, differentiation has been supported by the presence of significant increases in the gene expression of Desmin and MHC, which represent essential proteins for proper muscular structure and function (Fig. 4).

In particular, MHC was assessed at different time points (T0, 3, 6, 9 days) in order to follow the effective myogenesis over time (Fig. 4f). Since MHC is one of the most important proteins in skeletal muscle, and it is essential for contraction and muscle movement, it was analyzed by immunofluorescence staining. The microscopic observation of hSkMCs 


\section{A

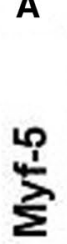

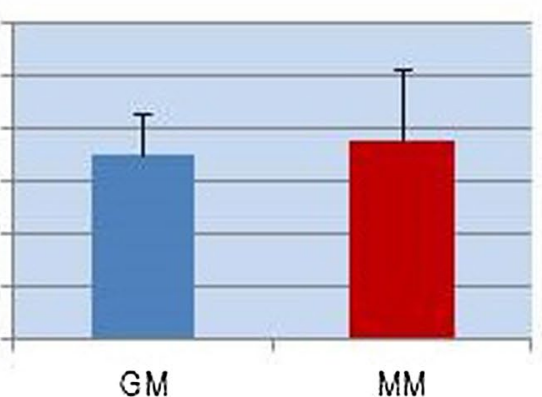

$G M$

MM

C

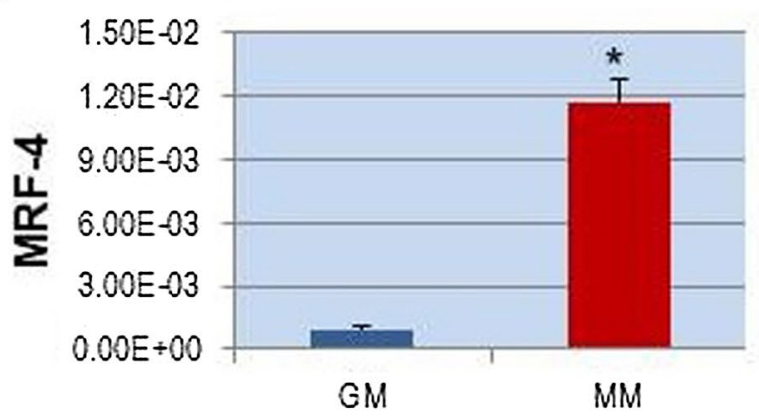

E

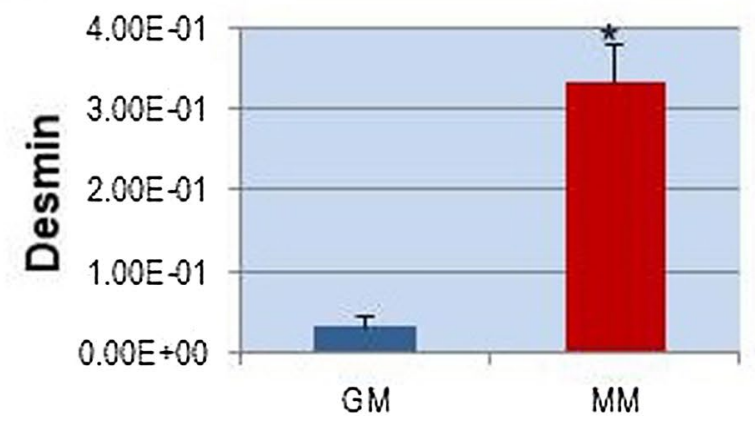

Fig. 4 Real-Time qPCR analysis of the main genes during in vitro myogenesis of hSkMCs, in proliferation (red), and after 9 days of myogenic induction in DM (blue). Values are the mean \pm SD of

after 9 days in MM has shown the presence of MHC, demonstrating the suitability of our in vitro myogenesis model (Fig. 5).

\section{Gene Expression Analysis of Hormone Receptors in hSkMCs During In Vitro Myogenesis}

The hSkMCs were differentiated using the MM and, after 9 days of induction, we analyzed the gene expression of the hormone receptors, in order to characterize the maturation and endocrine properties of the cellular model during myogenesis. In particular, we analyzed the following genes by Real-Time qPCR: VDR, TR $\alpha$, TR $\beta$, GCR, PTH-1R, IFG-1R, LRP-5, LRP-6 and Irisin.

\section{B}

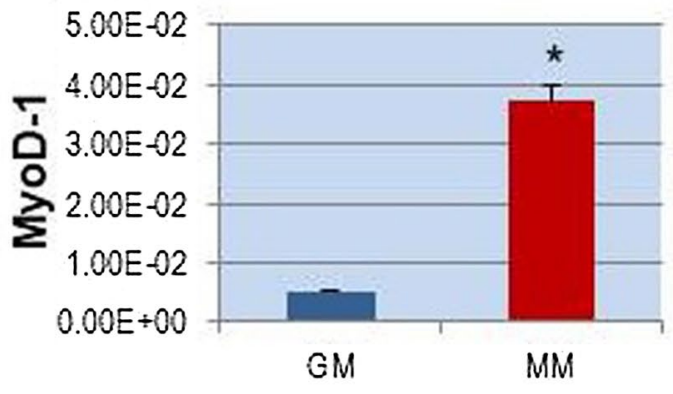

D

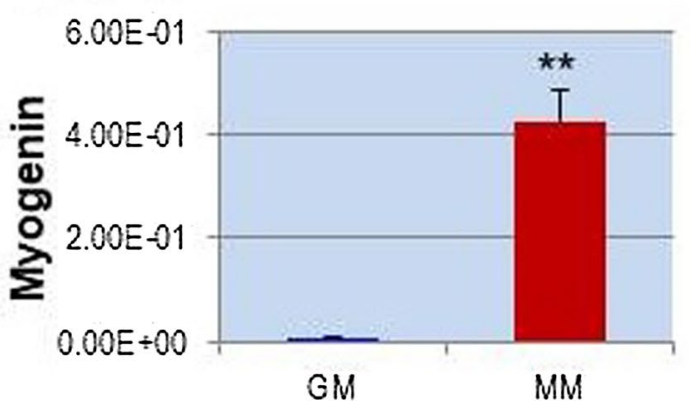

$\mathbf{F}$

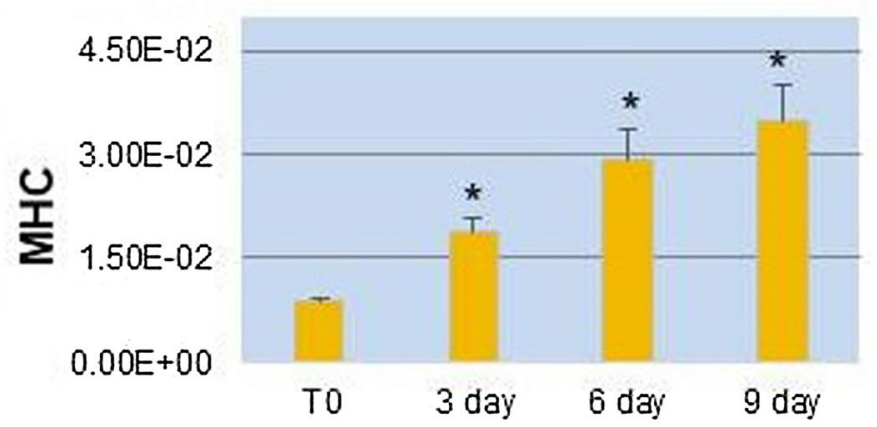

3 independent experiments and they are expressed as the number of mRNA molecules of the genes normalized to the housekeeping RPS18 mRNA. ${ }^{*} p<0.001, * * p<0.005$ versus control group in GM

The results of the hormone receptors analyzed have shown significant increases in gene expressions during cell differentiation with respect to the control group in growth medium, demonstrating the formation of the skeletal muscle as an endocrine apparatus during myogenesis (Fig. 6). Subsequently, the expression of Irisin, a hormone secreted by skeletal muscle, specifically suggests the development and maturation of new myofibers, since it represents a myokine secreted by mature endocrine tissue. 
Fig. 5 Microscopic observations in LSCM of MHC in hSkMCs after 9 days of myogenic induction (Alexa Fluor 488 , conventional green color). Nuclei counterstained with propidium iodide in conventional red color. Objective $\times 20(\mathbf{a})$ and $\times 40(\mathbf{b})$
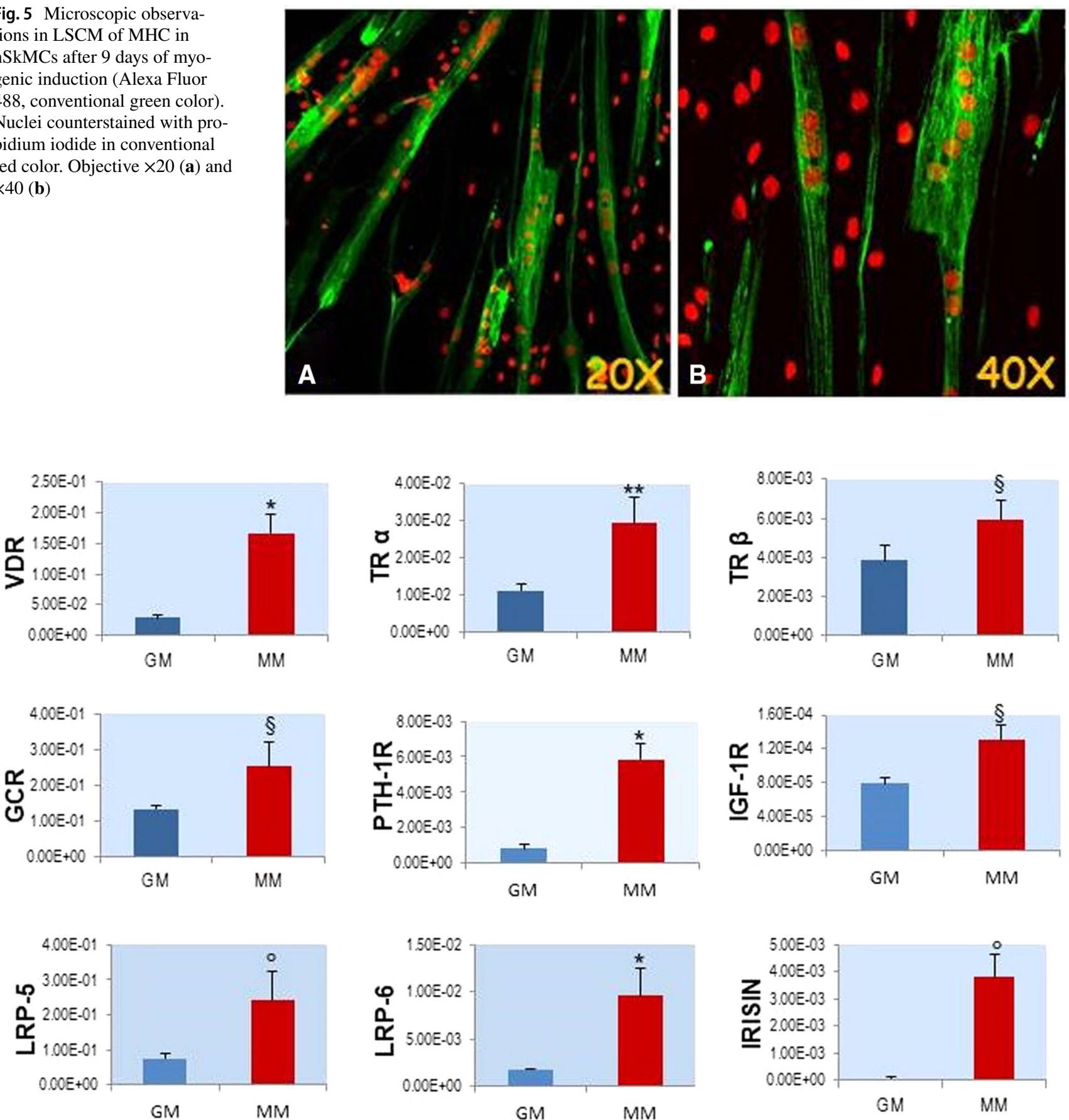

Fig. 6 Real-Time qPCR of the hormone receptor genes during in vitro myogenesis of hSkMCs, in proliferation (red) and after 9 days of myogenic induction in DM (blue). Values are the mean \pm SD of 3 independent experiments and they are expressed as the num-

ber of mRNA molecules of the genes normalized to RPS18 mRNA. ${ }^{*} p<0.001, * * p<0.005,{ }^{\circ} p<0.01,{ }^{\S} p<0.05$ versus control group in $\mathrm{GM}$

\section{Discussion}

The last decade has been an exciting period for the study of the biology of skeletal muscle stem cells and tissue regeneration and the development of novel human in vitro cell models can contribute to the identification of new mechanisms that control myogenesis [14-20]. These human cell cultures appear more suitable for predictive screening strategies when compared to rodent cell lines, such as $\mathrm{C} 2 \mathrm{C} 12$ or rat L6 myoblasts [21, 22]. 
In this study, we have isolated and characterized skeletal muscle-derived cells from human biopsies to be used for the in vitro study of myogenesis. The developed cellular model was enriched in satellite cells, as confirmed by analyzing the presence of PAX-7 in more than $99 \%$ of the hSkMCs and the disappearance of the PAX-7 gene with each passage in culture [23]. For this reason, we decided to use cells not over the fourth passage in vitro.

Although CD34 antigen is a marker of satellite cells in murine models, our results indicate that, in human SCs, CD34 expression is not the hallmark of SCs, as it is present in only $0.5 \%$ of hSkMCs [24]. The same is true for CD56 antigen, which is present in only $9 \%$ of the isolated hSkMCs, a result that may be controversial considering other data in the literature, since it also marks natural killer lymphocytes $[25,26]$. Flow cytometry analysis in hSkMCs has permitted the verification of the presence of the principal markers to be expressed on the surface of mesenchymal stem cells, specifically CD44, CD105 and CD90, and the negativity of the hematopoietic CD45 antigen, confirming the mesenchymal stemness of our cells, as largely recognized in the literature. The multipotentiality of the isolated hSkMCs was confirmed by demonstrating their own capacity to differentiate into the adipogenic, osteogenic and myogenic phenotypes, as assessed by cytochemical staining performed on cells, properly induced with specific differentiating media, as reported in the literature [27].

Using appropriate differentiation medium with confluent cells at $70-80 \%$ density in the plate, we were able to induce the alignment of the activated cells (myoblasts), the subsequent fusion with each other and, finally, the differentiation into multinucleated myofibers. Gene expression analyses have shown significant increases of MRFs, MyoD-1, MRF4, and Myogenin, 9 days after myogenic induction which, together with Desmin and MHC gene expression augmentation during the entire study period, have confirmed myoblast determination and muscle differentiation, confirming the suitability of our in vitro myogenesis model. The only non-significance increase in gene expression was detected for the Myf-5 gene, in agreement with data reported in the literature. The reason may the fact that this transcription factor is the main controller of the activation of SCs toward myogenic differentiation and is expressed in a majority of quiescent SCs in adult muscle [3]. It is also reported that Myf-5, in the absence of MyoD-1, MRF-4 and Myogenin during development, is unable to drive myogenic differentiation, so Myf-5 may contribute to controlling "stemness" in the niche [4] [28].

Once validated the in vitro model, we embarked in the project of characterization of the endocrine machinery in the different stages of myocytic differentiation. This analysis was never performed before in in vitro models. The analysis was focused on selected receptor genes known to mediate a specific hormonal action on skeletal muscle tissue or suggested to mediate an endocrine action on skeletal muscles: VDR, TR $\alpha$, TR $\beta$, IGF-1R, PTH-1R, GCR, LRP-5 and LRP-6.

In the literature, it has been reported that vitamin D deficiency is a condition associated with skeletal muscle weakness and small muscle fiber size [29]. In animal models, the skeletal muscle dysfunction observed in vitamin D deficiency is reversed by vitamin D repletion, whereas vitamin D supplementation in humans has been found to increase skeletal muscle strength [30]. Many reports suggest that the VDR is expressed in skeletal muscle [31]. VDR deletion in mice results in alterations in muscle function and strength [32], and its association with interleukin-6 may play a role in intramuscular inflammation [33].

The thyroid hormone plays an essential role in myogenesis; it acts as a pleiotropic factor during development and regulates genes involved in growth and differentiation [34, 35]. In particular, data on $\mathrm{C} 2 \mathrm{C} 12$ cells and primary myoblasts from mice have suggested the essential role of TR $\alpha$ in the optimal fusion and regeneration of myofibers after muscle injury and to maintain the SC niche during aging [36, 37]. Moreover, it has been reported that TR $\alpha$ is the dominant isoform thyroid receptor in $\mathrm{C} 2 \mathrm{C} 12$ and murine primary myoblasts. This is in agreement with our results in which mRNA expression is higher for TR $\alpha$ with respect to TR $\beta$.

Insulin-like Growth Factor-1 (IGF-1), the mediator of growth hormone function, strongly promotes the proliferation and differentiation of skeletal myoblasts. The anabolic effects of IGF-1 are mediated through specific binding with IGF-1R to promote the activation of the PI3K/art/mTOR signaling pathway, which is associated with protein synthesis and muscle hypertrophy [38, 39]. Moreover, IGF$1 \mathrm{R}$ is required for normal muscle growth, and its loss on mouse muscle leads to increased basal glucose uptake due to increases in levels of Glu1 and Glu4 transporters, chronic activation of Akt and AMPK signaling, and a loss of TBC1D1, data confirmed also in L6 myotubes [40].

Regarding parathyroid hormone (PTH) and its receptor (PTH-1R), very few data in the literature are reported about their effects on skeletal muscle cells. PTH has been shown to enhance the differentiation of mesoderm to various cell types, including osteoblasts and smooth muscle cells [41, 42]. Since skeletal muscle cells are derived from the mesoderm, it is conceivable that PTH may also influence the differentiation of these cells. It has been reported that PTH and the expression of PTH-1R accelerate the differentiation of SCs to myotubes in a mouse model [43].

Skeletal muscle is a notable target for glucocorticoids (GCs) in health and disease. GCs convey their signals mainly through an intracellular glucocorticoid receptor (GCR). Chronically increased levels of endogenous or exogenous GCs can lead to proteolysis, muscle wasting, myopathy, and 
induce insulin resistance with severe perturbation in systemic energy metabolism, while short exposures to high GC concentrations have been involved in the development of crucial illness myopathy $[44,45]$. Despite its importance, data on GC signaling during human skeletal muscle regeneration and how GCR primary target genes confer metabolic function of GCs remain incomplete [46]. In the literature, it has been reported that GCR is involved in a positive regulation of muscle regulatory gene Myf-5 in the mouse myogenic cell line $\mathrm{C} 2$ [47].

LRP-5 and LRP-6 are highly homologous proteins with key functions in canonical Wnt signaling. Alteration in genes encoding these receptors or their interacting proteins is linked to human diseases and, for that reason, they have been a major focus of drug development efforts to treat several human conditions, including osteoporosis, cancer and metabolic disease [48]. Sclerostin is a circulating osteocytederived glycoprotein produced by the osteocytes that in a paracrine fashion negatively regulates Wnt signaling after binding the LRP5/LRP6 co-receptors in osteoblastic cells and its pharmacologic inhibition produces bone anabolic effects [49]. Conversely, endocrine effects of sclerostin on muscle morphology remain unknown, and very little data are reported in the literature [50].

In the present study, the genes encoding the receptors for the above outlined hormones were detected in a limited number of collected hSkMCs. Moreover, all the assayed receptor genes significantly increase during in vitro myogenesis of hSkMCs, supporting their role in the maturation of the human skeletal muscle. The fact that the two sclerostin receptors LRP-5 and LRP-6 are expressed in hSkMCs is opens for this important osteocytic protein a function as a hormone in the reciprocal interaction between bone and skeletal muscle. Interestingly, also the expression of the gene encoding Irisin, an important hormone produces by mature skeletal muscle tissue that affects cortical bone [51] increases during the process of in vitro differentiation of the hSkMCs.

\section{Conclusions}

In conclusion, our results have demonstrated the utility of skeletal muscle satellite cells, isolated from human biopsies, as an in vitro cell model to study the myogenesis process and the characterization of the skeletal muscle as an endocrine apparatus and a target organ for several hormones. In fact, all the assayed hormone receptor genes may represent feasible targets during skeletal muscle regeneration to be modulated throughout the skeletal muscle differentiation pathway. Similarly, muscle function should be evaluated in patients suffering of various endocrinopathies, a problem not routinely carried out by the endocrinologists. These findings could stimulate further research for a better understanding of disorders associated with impaired adult myogenesis, to help identify novel therapeutic interventions for these conditions. Future developments of this research will include the enlargement of the culture collection and the characterization of the novel evidenced targets in human skeletal myogenesis.

Acknowledgments This study was funded and supported by the MIUR-PRIN2012_Muskendo (Protocol 2012227FLF) (to MLB), by the H2020, Excellent science, Marie Skłodowska-Curie Innovative Training Networks_CaSR Biomedicine (Grant Agreement No. 675228) (to MLB) and by the Fondazione Italiana sulla Ricerca per le Malattie dell'Osso (to MLB).

Author Contribution CR, RZ, LC, MLB conceived and designed the project; MI provided biopsies; CR, RZ developed the cellular model; $\mathrm{CR}, \mathrm{RZ}, \mathrm{PS}$ acquired the data; CR, RZ analyzed and interpreted the data; CR wrote the manuscript; MLB is guarantor. All authors have read and approved the final manuscript.

\section{Compliance with Ethical Standards}

Conflict of interest The authors declare that they have no conflict of interest.

Ethical Approval All procedures performed in studies involving human participants were in accordance with the ethical standards of the institutional and/or national research committee AOU Careggi and with the 1964 Helsinki declaration and its later amendments or comparable ethical standards.

Informed Consent All participants provided an informed written consent prior to inclusion.

Open Access This article is licensed under a Creative Commons Attribution 4.0 International License, which permits use, sharing, adaptation, distribution and reproduction in any medium or format, as long as you give appropriate credit to the original author(s) and the source, provide a link to the Creative Commons licence, and indicate if changes were made. The images or other third party material in this article are included in the article's Creative Commons licence, unless indicated otherwise in a credit line to the material. If material is not included in the article's Creative Commons licence and your intended use is not permitted by statutory regulation or exceeds the permitted use, you will need to obtain permission directly from the copyright holder. To view a copy of this licence, visit http://creativecommons.org/licenses/by/4.0/.

\section{References}

1. Wang Y, Rudnicki M (2011) Satellite cells, the engines of muscle repair. Nat Rev Mol Cell Biol 13:127-133. https://doi. org/10.1038/nrm3265

2. Mauro A (1961) Satellite cell of skeletal muscle fibers. J Biophys Biochem Cytol 9:493-495. https://doi.org/10.1083/ jcb.9.2.493

3. Tedesco F, Dellavalle A, Diaz-Manera J et al (2010) Repairing skeletal muscle: regenerative potential of skeletal muscle stem 
cells. J Clin Invest 120(1):11-19. https://doi.org/10.1172/JCI40 373

4. Zammit P (2017) Function of the myogenic regulatory factors Myf5, MyoD, Myogenin and MRF4 in skeletal muscle, satellite cells and regenerative myogenesis. Semin Cell Dev Biol 72:19-32. https://doi.org/10.1016/j.semcdb.2017.11.011

5. Chen B, Shan T (2019) The role of satellite and other functional cell types in muscle repair and regeneration. J Muscle Res Cell Motil. https://doi.org/10.1007/s10974-019-09511-3

6. Pederson B (2013) Muscle as a secretory organ. Compr Physiol 3:1337-1362. https://doi.org/10.1002/cphy.c120033

7. Yoon J, Kim J, Song P et al (2012) Secretomics for skeletal muscle cells: a discovery of novel regulators? Adv Biol Regul 52:340-350. https://doi.org/10.1016/j.jbior.2012.03.001

8. Ohlendieck K (2013) Proteomic identification of biomarkers of skeletal muscle disorders. Biomark Med 7:169-186. https://doi. org/10.2217/bmm.12.96

9. Romagnoli C, Pampaloni B, Brandi ML (2019) Muscle endocrinology and its relation with nutrition. Aging Clin Exp Res 31(6):783-792. https://doi.org/10.1007/s40520-019-01188-5

10. Juhas M, Ye J, Bursac N (2016) Design, evaluation, and application of engineered skeletal muscle. Methods 99:81-90. https:// doi.org/10.1016/j.ymeth.2015.10.002

11. Romagnoli C, Zonefrati R, Puppi D, Rosati C, Aldinucci A et al (2017) Human adipose tissue-derived stem cells and a poly( $\varepsilon$-caprolactone) scaffold produced by computer-aided wet spinning for bone tissue engineering. J Biomater Tissue Eng 7(8):622-633. https://doi.org/10.1166/jbt.2017.1614

12. Romagnoli C, Zonefrati R, Galli G, Puppi D et al (2015) In vitro behavior of human adipose tissue-derived stem cells on poly( $\varepsilon$-caprolactone) film for bone tissue engineering applications. Biomed Res Int 2015:323571. https://doi. org/10.1155/2015/323571

13. Nardone V, Zonefrati R, Mavilia C, Romagnoli C, Ciuffi S et al (2015) In vitro effects of strontium on proliferation and osteoinduction of human preadipocytes. Stem Cells Int 2015:871863. https://doi.org/10.1155/2015/871863

14. Nehlin JO, Just M, Rustan AC, Gaster M (2011) Human myotubes from myoblast cultures undergoing senescence exhibit defects in glucose and lipid metabolism. Biogerontology 12:349-365. https://doi.org/10.1007/s10522-011-9336-5

15. Broholm C, Laye MJ, Brandt C, Vadalasetty R, Pilegaard H, Krarlund Pedersen B, Scheele C (2011) LIF is a contractioninduced myokine stimulating human myocyte proliferation. J Appl Physiol 111:251-259. https://doi.org/10.1152/japplphysi ol.01399.2010

16. Davegardh C, Broholm C, Perfilyev A, Henriksen T, GarcíaCalzon S, Peijs L, Schioler Hansen N, Volkov P, Kjobsted R, Wojtaszewski JFP, Pedersen M, Krarlund Pedersen B, Ballak DB, Dinarello CA, Heinhuis B, Joosten LAB, Nilsson E, Vaag A, Scheele C, Ling C (2017) Abnormal epigenetic changes during differentiation of human skeletal muscle stem cells from obese subjects. BMC Med 15:39-65. https://doi.org/10.1186/s1291 6-017-0792-x

17. Riddle ES, Bender EL, Thalacker-Mercer AE (2018) Transcript profile distinguishes variability in human myogenic progenitor cell expansion capacity. Physiol Genomics 50:817-827. https:// doi.org/10.1152/physiolgenomics.00041.2018

18. Riddle ES, Bender EL, Thalacker-Mercer AE (2018) Expansion capacity of human muscle progenitor cells differs by age, sex, and metabolic fuel preference. Am J Physiol Cell Physiol 315:C643C652. https://doi.org/10.1152/ajpcell.00135.2018

19. Gheller BJ, Blum J, Souied-Baumgarten S, Bender E, Cosgrove BD, Thalacker-Mercer A (2019) Isolation, culture, characterization, and differentiation of human muscle progenitor cells from the skeletal muscle biopsy procedure. JOVE 150:e59580. https:// doi.org/10.3791/59580

20. Kugler BA, Gundersen AE, Li J, Deng W, Eugene N, Gona PN, Houmard JA, Zou K (2019) Roux-en-Y gastric bypass surgery restores insulin-mediated glucose partitioning and mitochondrial dynamics in primary myotubes from severely obese humans. Int J Obesity. https://doi.org/10.1038/s41366-019-0469-y

21. Sultan K, Henkel B, Terlou M, Haagsman H (2006) Quantification of hormone-induced atrophy of large myotubes from $\mathrm{C} 2 \mathrm{C} 12$ and L6 cells: atrophy-inducible and atrophy-resistant C2C12 myotubes. Am J Physiol Cell Physiol 290:C650-C659. https://doi. org/10.1152/ajpcell.00163.2005

22. Cui Z, Chen X, Lu B, Park S et al (2009) Preliminary quantitative profile of differential protein expression between rat L6 myoblasts and myotubes by stable isotope labeling with amino acids in cell culture. Proteomics 9:1274-1292. https://doi.org/10.1002/ pmic. 200800354

23. Yokoyama S, Asahara H (2011) The myogenic transcriptional network. Cell Mol Life Sci 68(11):1843-1849. https://doi. org/10.1007/s00018-011-0629-2

24. Bareja A, Holt J, Luo G, Chang C et al (2014) Human and mouse skeletal muscle stem cells: convergent and divergent mechanisms of myogenesis. PLoS ONE 9(2):e90398. https://doi.org/10.1371/ journal.pone.0090398

25. Trapecar M, Kelc R, Gradisnik L, Vogrin M, Rupnik M (2014) Myogenic progenitors and imaging single-cell flow analysis: a model to study commitment of adult muscle stem cells. J Muscle Res Cell Motil 35(5-6):249-257. https://doi.org/10.1007/s1097 4-014-9398-5

26. Illa I, Leon-Monzon M, Dalakas M (1992) Regenerating and denervated human muscle fibers and satellite cells express neural cell adhesion molecule recognized by monoclonal antibodies to natural killer cells. Ann Neurol 31(1):46-52. https://doi.org/10.1002/ ana.410310109

27. Asakura A, Komaki M, Rudnicki M (2001) Muscle satellite cells are multipotential stem cells that exhibit myogenic, osteogenic, and adipogenic differentiation. Differentiation 68:245-253. https ://doi.org/10.1046/j.1432-0436.2001.680412.x

28. Valdez M, Richardson J, Klein W, Olson E (2000) Failure of Myf5 to support myogenic differentiation without myogenin, MyoD, and MRF4. Dev Biol 219(2):287-298. https://doi.org/10.1006/ dbio.2000.9621

29. Girgis C, Clifton-Bligh R, Hamrick M, Holick M, Gunton J (2013) The roles of vitamin D in skeletal muscle: form, function, and metabolism. Endocr Rev 34(1):33-83. https://doi.org/10.1210/ er.2012-1012

30. Beaudart C, Buckinx F, Rabenda V, Gillain S et al (2014) The effects of vitamin D on skeletal muscle strength, muscle mass, and muscle power: a systematic review and meta-analysis of randomized controlled trials. J Clin Endocrinol Metab 99(11):43364345. https://doi.org/10.1210/jc.2014-1742

31. Tanaka M, Kishimoto K, Okuno H, Saito H, Itoi E (2014) Vitamin $\mathrm{D}$ receptor gene silencing effects on differentiation of myogenic cell lines. Muscle Nerve 49(5):700-708. https://doi.org/10.1002/ mus. 23950

32. Endo I, Inoue D, Mitsui T, Umaki Y, Akaike M et al (2003) Deletion of vitamin D receptor gene in mice results in abnormal skeletal muscle development with deregulated expression of myoregulatory transcription factors. Endocrinology 144(12):5138-5144. https://doi.org/10.1210/en.2003-0502

33. Pojednic R, Ceglia L, Lichtenstein A, Dawson-Hughes B, Fielding $\mathrm{R}$ (2015) Vitamin D receptor protein is associated with interleukin-6 in human skeletal muscle. Endocrine 49(2):512-520. https ://doi.org/10.1007/s12020-014-0505-6 
34. Lee J, Kim N, Milanesi A (2014) Thyroid hormone signaling in muscle development, repair and metabolism. J Endocrinol Diabetes Obes 2(3): 1046

35. Bloise F, Oliveira T, Cordeiro A, Ortiga-Carvalho T (2018) Thyroid hormones play role in sarcopenia and myopathies. Front Physiol 9:560. https://doi.org/10.3389/fphys.2018.00560

36. Milanesi A, Lee J, Kim N, Liu Y et al (2016) Thyroid hormone receptor $\alpha$ plays an essential role in male skeletal muscle myoblast proliferation, differentiation, and response to injury. Endocrinology 157(1):4-15. https://doi.org/10.1210/en.2015-1443

37. Milanesi A, Lee J, Yang A, Liu Y, Sedrakyan S et al (2017) Thyroid hormone receptor alpha is essential to maintain the satellite cell niche during skeletal muscle injury and sarcopenia of aging. Thyroid 27(10):1316-1322. https://doi.org/10.1089/thy.2017.0021

38. Retamales A, Zuloaga R, Valenzuela C, Gallardo-Escarate C et al (2015) Insulin-like growth factor-1 suppresses the Myostatin signaling pathway during myogenic differentiation. Biochem Biophys Res Commun 464(2):596-602. https://doi.org/10.1016/j. bbrc.2015.07.018

39. Glass D (2010) PI3 kinase regulation of skeletal muscle hypertrophy and atrophy. Curr Top Microbiol Immunol 346:267-278. https://doi.org/10.1007/82_2010_78

40. O’Neill B, Lauritzen H, Hirshman M, Smyth G et al (2015) Differential role of insulin/IGF-1 receptor signaling in muscle growth and glucose homeostasis. Cell Rep 11(8):1220-1235. https://doi. org/10.1016/j.celrep.2015.04.037

41. Zhang K, Wang M, Li Y, Li C et al (2019) The PERK-EIF2 $\alpha$ ATF4 signaling branch regulates osteoblast differentiation and proliferation by PTH. Am J Physiol Endocrinol Metab 316(4):E590-E604. https://doi.org/10.1152/ajpendo.00371.2018

42. Song G, Fiaschi-Taesch N, Bisello A (2009) Endogenous parathyroid hormone-related protein regulates the expression of PTH type 1 receptor and proliferation of vascular smooth muscle cells. Mol Endocrinol 23:1681-1690. https://doi.org/10.1210/me.2009-0098

43. Kimura S, Yoshioka K (2014) Parathyroid hormone and parathyroid hormone type-1 receptor accelerate myocyte differentiation. Sci Rep 4:5066. https://doi.org/10.1038/srep05066
44. Menconi M, Gonnella P, Petkova V, Lecker S, Hasselgren P (2008) Dexamethasone and corticosterone induce similar, but not identical, muscle wasting responses in cultured $\mathrm{L} 6$ and $\mathrm{C} 2 \mathrm{C} 12$ myotubes. J Cell Biochem 105(2):353-364. https://doi.org/10.1002/ jcb. 21833

45. Filipović D, Pirkmajer S, Mis K (2011) Mars T and Grubic Z (2011) Expression of glucocorticoid receptors in the regenerating human skeletal muscle. Physiol Res 60(1):S147-S154 PMID: 21777031

46. Kuo T, Harris C, Wang J (2013) Metabolic functions of glucocorticoid receptor in skeletal muscle. Mol Cell Endocrinol 380(12):79-88. https://doi.org/10.1016/j.mce.2013.03.003

47. Auradé F, Pfarr C, Lindon C, Garcia A et al (1997) The glucocorticoid receptor and AP-1 are involved in a positive regulation of the muscle regulatory gene myf5 in cultured myoblasts. J Cell Sci 110(Pt 22):2771-2779 PMID: 9427286

48. Joiner D, Ke J, Zhong Z, Xu H, Williams B (2013) LRP5 and LRP6 in development and disease. Trends Endocrinol Metab 24(1):31-39. https://doi.org/10.1016/j.tem.2012.10.003

49. Moester M, Papapoulos S, Löwik C, van Bezooijen R (2010) Sclerostin: current knowledge and future perspectives. Calcif Tissue Int 87(2):99-107. https://doi.org/10.1007/s00223-010-9372-1

50. Phillips E, Beggs L, Ye F, Conover C et al (2018) Effects of pharmacologic sclerostin inhibition or testosterone administration on soleus muscle atrophy in rodents after spinal cord injury. PLoS ONE 13(3):e0194440. https://doi.org/10.1371/journal.pone.01944 40

51. Colaianni G, Cinti S, Colucci S, Grano M (2017) Irisin and musculoskeletal health. Ann N Y Acad Sci 1402(1):5-9. https://doi. org/10.1111/nyas. 13345

Publisher's Note Springer Nature remains neutral with regard to jurisdictional claims in published maps and institutional affiliations. 